\title{
POPs in ambient air from MONET network - global and regional trends
}

\author{
I. Holoubek, J. Klánová, P. Čupr, P. Kukučka, J. Borůvková, \\ J. Kohoutek, R. Prokeš \& R. Kareš \\ RECETOX, Masaryk University, Brno, Czech Republic
}

\begin{abstract}
The Stockholm Convention (SC) on Persistent Organic Pollutants (POPs) mentioned in Article 16 of the SC that its effectiveness shall be evaluated starting four years after the date of its entry into force. Global Monitoring Plan (GMP) has been developed with an objective of evaluating whether the POPs actually were reduced or eliminated on the global scale. As one of the key matrices for the global monitoring, an ambient air was selected. We are using two approaches for sampling - so called active using the high volume samplers, and passive air samplers (PAS) as new tools for the air quality monitoring.

MONET programme (MONnitoring NETwork) is driven by RECETOX as the Regional Centre of the Stockholm Convention for the region of Central and Eastern Europe on the national scale (MONET-CZ, containing 37 sites including 15 backgrounds), and regional scales - the Central, Southern and Eastern Europe and Central Asia (MONET-CEECs), the Pacific Islands (MONET-PIs), the African continent (MONET-AFRICA) and newly the whole of Europe (MONET-Europe). Samples are collected every 28 days; it represents 13 samples from each site every year.

Keyword: Stockholm Convention, persistent organic pollutants (POPs), ambient air monitoring.
\end{abstract}

\section{Introduction - Stockholm Convention on POPs and their effectiveness evaluation}

The Stockholm Convention on Persistent Organic Pollutants (POPs) [1] entered into force on the May 17, 2004 and has currently 173 signatory parties (May 16, 2011). The main objective of the Stockholm Convention (SC) is to protect 
human health and the environment from persistent organic pollutants by reducing or eliminating their releases into the environment.

A term "persistent organic pollutants" (POPs) represents several classes of organic chemicals including polychlorinated dibenzo- $p$-dioxins and furans (PCDDs/Fs), polychlorinated biphenyls (PCBs), organochlorine pesticides (OCPs) and other industrial and agricultural chemicals. Due to their wide distribution, ability to accumulate in abiotic matrices such as soils or sediments with high contents of organic matter, bioaccumulate in the biotic tissues, and potential harmful effects such as immunotoxicity, neurotoxicity, developmental toxicity, carcinogenicity, mutagenicity, and endocrine disruption potentials, POPs have remained at the centre of scientific attention for the last few decades. Polycyclic aromatic hydrocarbons (PAHs) are often included in this group of compounds because of their potential for long-range transport even though their physicochemical properties do not suggest the persistency and bioaccumulation potential.

According to Article 16 of the Convention, its effectiveness shall be evaluated starting four years after the date of its entry into force, and periodically thereafter at every 6 years [1]. Each effectiveness evaluation should consist of reports and environmental monitoring information pursuant to paragraph 2 of Article 16, and national reports pursuant to Article 15 (reports on the measures taken by the Parties, and the effectiveness of those measures). For the first of these elements, the Guidance of Global monitoring was prepared and its main goal is development and implementation of the arrangements to provide comparable monitoring information on the presence of the chemicals listed in Annexes A, B and $\mathrm{C}$ of the Convention in ambient air and human milk, as well as their regional and global environmental transport.

The objectives of the POPs Global Monitoring Plan are to evaluate whether the POPs actually were reduced or eliminated as requested in Articles 3 and 5 of the Convention which means that information on environmental levels of the chemicals listed in the annexes should enable detection of trends over time [1]. Therefore focus is upon monitoring of background levels of POPs at locations not influenced by local sources. Reliable identification of trends will require that statistical evaluation is carried out on the design of each national monitoring program contributing to the Global Monitoring Plan, to ensure that it is powerful enough to detect trends in time. In order to meet the objectives of the Global Monitoring Plan (support the preparation of regional reports of comparable information on environmental background levels), the guidance must be provided on how information is to be collected, analyzed, statistically treated, and reported [2].

\section{Polyurethane foam BASED passive samplers for sampling of POPs in ambient air - background information}

As air pollution became an issue of great public health concern and the international conventions and new regulations introduced their demands, a pressing need to obtain more air pollutants including POPs data in a cost- 
effective way appeared. Global Monitoring Plan has been prepared for the purpose of the Stockholm Convention with the objective of establishing baseline trends at global background sites [2]. It was the main goal of the first step of this Global monitoring programme - the determination of basic global information in 2009. When developed parties are to conduct source inventories, identify ongoing sources, and provide environmental monitoring evidence that ambient levels of POPs are declining [2,3], developing countries in particular require cost-effective and simple approaches. The experiences from the first report in 2009 and including of newly adopted POPs, will be used for the second assessment in 2015.

Based on the long-term work of many international experts, the Guidance for the Global Monitoring Plan [2], was prepared. As one of the key matrices, the ambient air was selected. We have two basic principles for the sampling of ambient air for POPs determination - so called active using the high volume air samplers and passive sampling. Since the high volume air samplers as expensive devices requiring reliable power supply as well as trained operators are not widely available, the air monitoring of POPs has only been conducted at limited number of sites. This was a reason, why in the last years, a lot of various new types of passive air samplers (PAS) as new tools for the air quality monitoring [3-6]. PAS represent a cheap and versatile alternative to the conventional high volume air sampling and they have been currently recommended as one of the methods suitable for the purpose of new long-term monitoring projects. They are capable of being deployed in many locations at the same time, which offers a new option for the large scale monitoring. As it provides information about longterm contamination of selected site, passive air sampling can be used as a screening method for semi-quantitative comparison of different sites with the advantage of low sensitivity to accidental short-time changes in concentration of pollutants.

It was demonstrated that passive air samplers using polyurethane foam (PUF) filters are suitable to study vapour-phase air concentrations of POPs, particularly of more volatile compounds [7-10], and they were successfully applied as a tool for POPs monitoring on the global, regional, national levels and also local scale where can provide site- and source-specific fingerprints and they can be used to conduct screening surveys to help to identify the sources $[9,10]$. This tool based on experiences and results from the long term testing and broad applications was recognized as very useful and effective for the determination of temporal, seasonal and spatial trends on the global, regional and local scales [11].

On the other hand, due to the sensitivity of PAS to local effects, sampling site selection seems to be crucial for the success of such projects since small-scale variability in each region can exceed the continental variability. To develop a monitoring network, the local conditions, sources of contamination and environmental variables must be evaluated very carefully since only detail characterization of potential local effects for every sampling site can assure the successful selection of sites for larger (regional or global) scale monitoring. Performing more detailed local screening studies before designing the final network is advisable. 


\section{RECETOX pilot studies}

Passive air samplers of this design were first introduced in the Czech Republic in 2002 during the European screening campaign performed by Lancaster University and focused on the atmospheric levels of POPs [7,12]. Since 2003, this research topic has been developed in the RECETOX in cooperation with Lancaster University and Environment Canada.

RECETOX conceptual approach and contribution to wide application of this method was oriented to the long-term study of effects of environmental variables to applicability of this technique for the long-term monitoring and determination of temporal, seasonal and spatial trends on the global, regional and local scales. Samplers were calibrated against the high volume samplers in the field conditions, and their sensitivity, capacity, robustness, as well as an influence of the various meteorological parameters on their performance were assessed [13]. PAS have been continuously deployed in the regular atmospheric monitoring of POPs in Košetice station since 2003 side by side with active samplers to compare information derived from both techniques.

A core network of the Czech Republic was significantly altered based on the evaluation of the results from the pilot study in 2005, This network consists from some urban and suburban areas, vicinity of the industrial sources mentioned in the SC as potential sources of POPs (chemical industry, cement industry, municipal and medical waste incinerators, remediation technologies), and the new set of background sampling sites was included in cooperation with the Czech Hydrometeorological Institute. This set consists of the mountain sites along the Czech borders and it was meant to evaluate the impact of the transboundary transport in this region. The new design was introduced and initiated in January, 2006. Thirteen 28-days samples were collected from each of 50 sampling sites [14]. This sampling period and frequency was/is used in main part of MONET sampling sites and campaigns. This monitoring network MONET-CZ is still flexible and allows further improvements. At the same time, the backbone of the network allows performance and advanced interpretation of the short term spin-off case studies.

The new design of the MONET-CZ sampling sites was introduced and initiated in January, 2006 [14]. This network was further reduced from 50 to 37 sites in January, 2007, freeing a capacity to perform detailed screening studies in 14 regions of the Czech Republic [15].

The feasibility of the long-term application of passive air samplers for the evaluation of persisting influence of the war damages on the atmospheric contamination of the Western Balkan region was assessed in this study. Results of this project were compared to those of previous high volume sampling campaigns (APOPSBAL Project) [16,17]. It was the first international RECETOX sampling campaign which was focused to the collecting an extended number of parallel air samples, to put the data from the short-term high volume sampling events into the right perspective, to gain more information about the spatial and temporal distribution of POPs, and to collect the samples from remote 
places, a passive air sampling (PAS) campaign was organized in Croatia, Serbia, Bosnia, Herzegovina, and Kosovo in 2004.

As Central, Southern and Eastern Europe is the region with a lack of data on the atmospheric POP, three screening campaigns were organized between 2006 and 2008 (MONET-CEECs). Sampling sites for the first phase of the MONETCEECs Project, have been selected in cooperation with the local partners in all participating countries $[18,19]$. A philosophy was the same as for the model network in the Czech Republic: 5-20 sampling sites were selected per country (according to the size of each country) and they were monitored for 5 months.

A background site was included in most countries as a potential candidate of background monitoring for the effectiveness evaluation of the Stockholm Convention. Whenever possible, gradient of other sites (rural, urban, industrial) was developed also to address the range of contamination, possible sources and spatial variations. Soil samples were collected from the air sampling sites as a part of the study. A design of the study was synchronized with the Czech passive air monitoring network (MONET-CZ) which provides continuous data.

In addition to the Central and Eastern European region (CEEC), 26 sites from the African continent (MONET-AFRICA) and 21 sites from the Central Asia (former Soviet Union countries as a part of MONET-CEECs) were monitored in 2008 and 3 sites from the Pacific Islands between 2006 and 2007 (MONET-PIs). MONET-AFRICA now continues by the second phase (2010-2012) [20-22].

Previous RECETOX studies $[10,11]$ confirmed that PAS are sensitive enough to mirror even small-scale differences, which makes them capable of monitoring of spatial, seasonal and temporal variations. Passive samplers can be used for point sources evaluation in the scale of several square kilometres or even less - from the local plants to diffusive emissions from transportations or household incinerators - as well as for evaluation of diffusive emissions from secondary sources. While not being sensitive to short time accidental releases passive air samplers are suitable for measurements of long-term average concentrations at various levels.

\section{Methods - sampler, sampling and analysis}

\subsection{Sampler description}

Passive air sampling device used in the pilot studies and MONET programme consists of two stainless steel bowls attached to the common axes to form a protective chamber for the polyurethane foam filter $[9,10]$. The filter is attached to the same rod and it is sheltered against the wet and dry atmospheric deposition, wind and UV light. Exposure times between four and twelve weeks enable determination of many compounds from the POP group. Average sampling rate was estimated to be $3.5-7 \mathrm{~m}^{3} /$ day which roughly corresponds to $100-200 \mathrm{~m}^{3}$ of the air sampled during four weeks of deployment.

Passive air samplers consisting of the polyurethane foam disks $(15 \mathrm{~cm}$ diameter, $1.5 \mathrm{~cm}$ thick, density $0.030 \mathrm{~g} \mathrm{~cm}^{-3}$, type $\mathrm{N} 3038$; Gumotex Breclav, Czech Republic) housed in the protective chambers were employed in this study. 
Sampling chambers were prewashed and solvent-rinsed with acetone prior to installation. All filters were prewashed, cleaned ( 8 hours extraction in acetone and 8 hours in dichloromethane), wrapped in two layers of aluminum foil, placed into zip-lock polyethylene bags and kept in the freezer prior to deployment. Exposed filters were wrapped in two layers of aluminum foil, labeled, placed into zip-lock polyethylene bags and transported in cooler at $5^{\circ} \mathrm{C}$ to the laboratory where they were kept in the freezer at $-18^{\circ} \mathrm{C}$ until the analysis. Field blanks were obtained by installing and removing the PUF disks at all sampling sites.

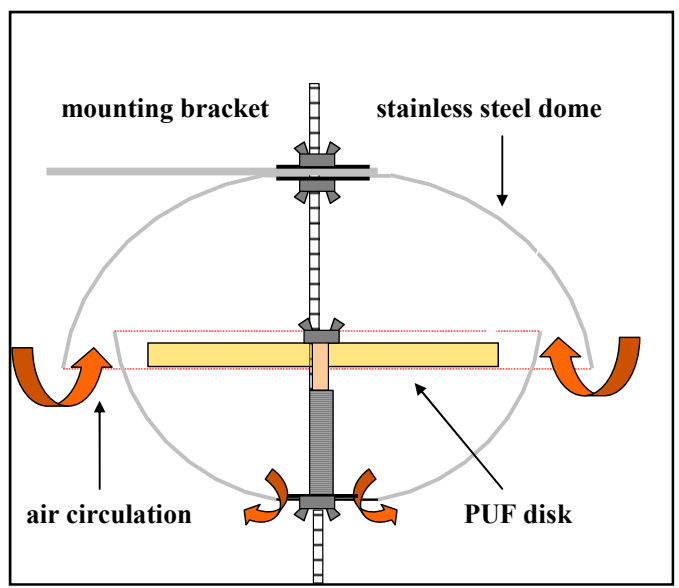

Figure 1: $\quad$ Scheme of the passive air sampler.

\subsection{Sample analysis}

All samples were extracted with dichloromethane in a Büchi System B-811 automatic extractor. One laboratory blank and one reference material were analyzed with each set of ten samples. Surrogate recovery standards ( $d 8$ naphthalene, d10-phenanthrene, d12-perylene for PAHs analysis, PCB 30 and PCB 185 for PCBs analysis) were spiked on each filter prior to extraction. Terfenyl and PCB 121 were used as internal standards for polyaromatic hydrocarbon (PAH) and polychlorinated biphenyl (PCB)/ organochlorine pesticide (OCP) analyses, respectively. Volume was reduced after extraction under a gentle nitrogen stream at ambient temperature, and fractionation achieved on a silica gel column; a sulphuric acid modified silica gel column was used for PCB/OCP samples. Samples were analyzed using GC-ECD (HP 5890) supplied with a Quadrex fused silica column 5\% Ph for PCBs: PCB 28, PCB 52, PCB 101, PCB 118, PCB 153, PCB 138, PCB 180, and OCPs: $\alpha-$ hexachlorocyclohexane $(\mathrm{HCH}), \beta-\mathrm{HCH}, \gamma-\mathrm{HCH}, \delta-\mathrm{HCH}, 1,1-$ dichloro-2,2-bis(pchlorfenyl)ethylene ( $p, p^{\prime}$-DDE), 1,1-dichloro-2,2-bis(p-chlorfenyl)ethan ( $p, p^{\prime}-$ DDD), 1,1,1-trichloro-2,2-bis(p-chlorfenyl)ethan ( $p, p^{\prime}$-DDT), o, $p^{\prime}$-DDE, $o, p^{\prime}$ DDD, $o, p^{\prime}$-DDE, hexachlorobenzene (HCB), and pentachlorobenzene (PeCB). 16 US EPA polycyclic aromatic hydrocarbons were determined in all samples 
using GC-MS instrument (HP 6890 - HP 5972) supplied with a J\&W Scientific fused silica column DB-5MS $[9,11,14,15]$.

\subsection{Quality assurance / quality control}

Recoveries were determined for all samples by spiking with the surrogate standards prior to extraction. Amounts were similar to detected quantities of analytes in the samples. Recoveries were higher than $76 \%$ and $71 \%$ for all samples for PCBs and PAHs, respectively. Recovery factors were not applied to any of the data. Recovery of native analytes measured for the reference material varied from 88 to $103 \%$ for PCBs, from 75 to $98 \%$ for OCPs, from 72 to $102 \%$ for PAHs. Laboratory blanks were under the detection limits for selected compounds. Field blanks consisted of pre-extracted PUF disks and they were taken on each sampling site. They were extracted and analyzed in the same way as the samples, and the levels in field blanks never exceeded 3\% of quantities detected in samples for PCBs, $1 \%$ for OCPs, $3 \%$ for PAHs, indicating minimal contamination during the transport, storage and analysis $[9,10,14,15]$.

\section{Results}

The passive samplers have been continuously co-employed with the high volume samplers as a part of the atmospheric monitoring of POPs in Kosetice since 2003. That allowed for the field calibration of PAS not only for the gas-phase chemicals but also for the particle-bound compounds. Five years of data are showing the same seasonal fluctuations as well as temporal trends as the results of the high volume monitoring (Fig. 2).

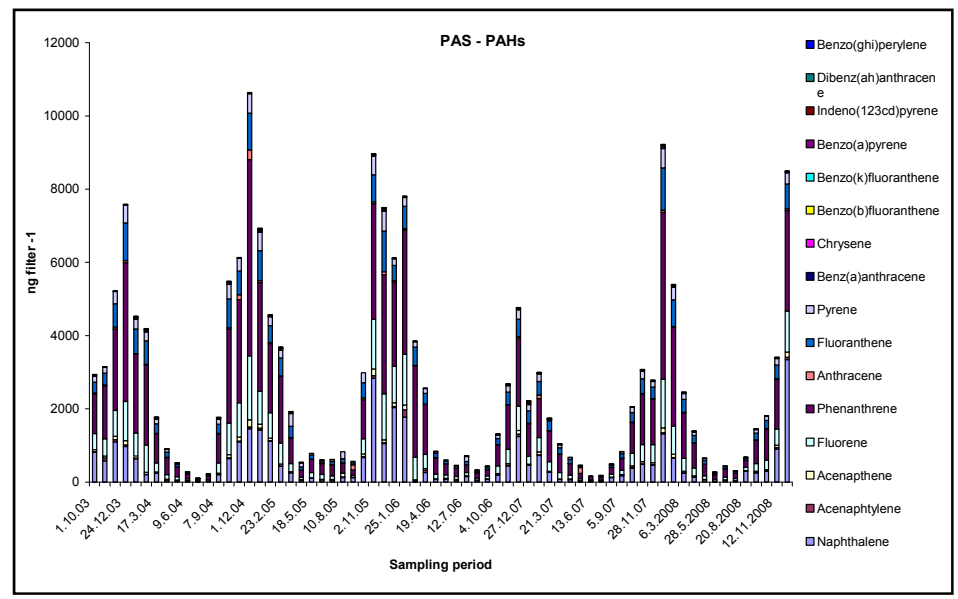

Figure 2: $\quad$ PAHs in ambient air (ng filter ${ }^{-1}$ ), Kosetice observatory, 2003-2008 (passive sampling). 
Example of the results from the first 3 years of the MONET network for PAHs (background sites only) is presented in Fig. 3 (winter months are shown in yellow, summer months in red color). We can see there the typical PAHs seasonal trends showing the winter maxima. But, we can also recognize, the variability of meteorological conditions. Temperatures during strong winter $2005 / 2006$ were much lower than the next winter and, as a reflection of these winter conditions, we can expect higher emissions of air pollutants including PAHs connected with the local heating systems. These higher emissions of PAHs are reflected in higher levels of PAHs in ambient air in all sites during the winter 2005/2006 in comparison with winter 2006/2007 [11].

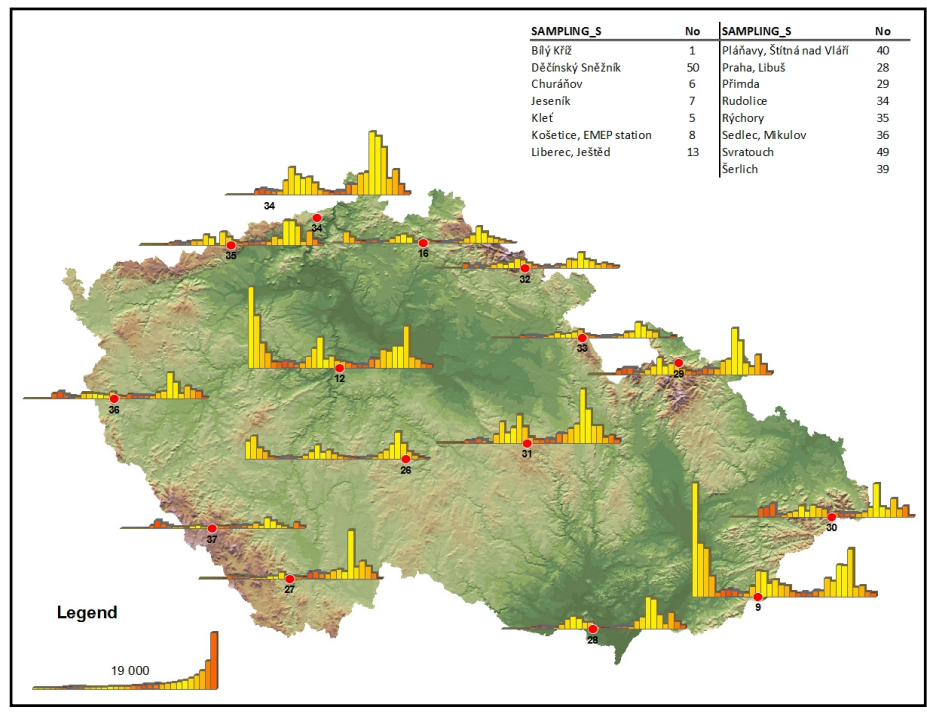

Figure 3: $\quad$ Passive air sampling 2006-2008, MONET-CZ, PAHs (ng filter ${ }^{-1}$ ).

For DDTs, fall concentrations were consistently the highest. Seasonal maxima of $\mathrm{HCHs}$ varied from site to site. Interestingly, $\mathrm{HCB}$ concentrations were higher in the winter rather than summer suggesting that combustion sources (seasonal residential heating) were more significant source of HCB than summer evaporation from diffusive secondary sources. No clear temporal trends have been observed yet.

\section{Future of MONET}

In case of the CEEC, it has been recognized that knowledge on Western European POP levels would greatly improve the understanding to CEEC data. Although Western Europe is formally a part of WEOG (Western Europe and Others Group) region, and the rest of Europe is reported under the CEEC, it is desirable to harmonize the monitoring activities in both parts of Europe to gain systematic information on the levels and trends of the atmospheric pollution in this continent. 
As the EMEP stations participating in the previous MONET activities seem to be the best candidates for the long-term background monitoring in many CEE countries (Czech Republic, Estonia, Latvia, Moldova, Slovakia, Slovenia), an agreement has been made between RECETOX and EMEP to organize a followup study as a joint activity of these partners. MONET stations from the previous campaigns were complemented by new stations from Western Europe to provide a good geographical coverage (Fig. 4 - MONET-Europe). The goal is to maintain sustainable PAS monitoring at the majority of sites. That would greatly improve the understanding to the sources, fate and transport of POPs in Europe and provide rich information for the modelling databases. At the same time, it would create necessary synergies between the Stockholm Convention and Convention on Long-Range Transboundary Air Pollution.

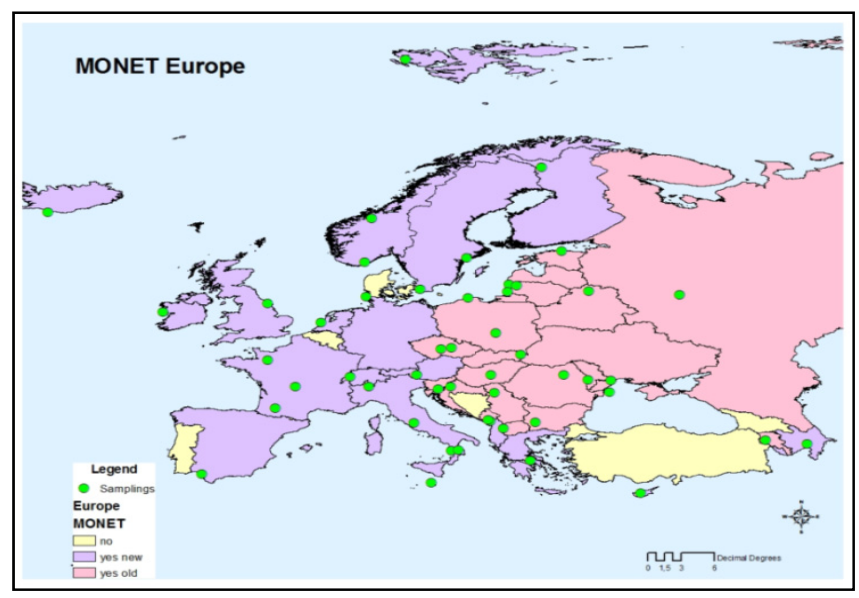

Figure 4: $\quad$ European passive air monitoring network.

RECETOX contributes very actively to the development and implementation of the Guidance for Global monitoring plan. For comparison - few years ago, only very limited number of sites with systematic and long-term monitoring of POPs in ambient air have been existed. It was not fully covered Europe (a part of EMEP Stations), Great Lakes region (IADN programme), Japan. Now due to the using of passive samplers, the present situation looks much better also with a significant contribution of data from the MONET networks.

In 2009, the Conference of the Parties of the SC decided that levels of POPs in core matrices will be assessed every six years assuming that such period will be sufficient for establishment of the temporal trends. As the Košetice station is the only site worldwide where active and passive samplers have been coemployed for full six years so far, results from this station have an important role in the intercalibration of both techniques, comparison of trends derived from both datasets, and development of future global monitoring programmes [1618]. Long-term sustainability of such monitoring programmes is of a great importance for a success of the Global monitoring plan. 


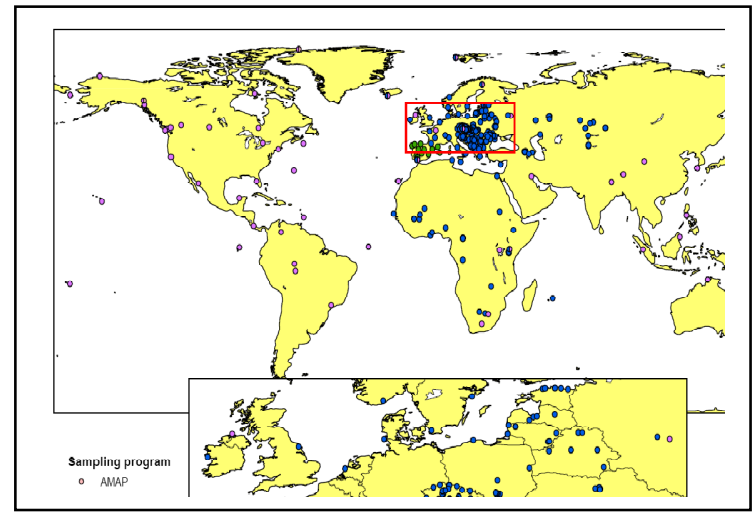

Figure 5: Global distribution of the sampling sites with on-going air monitoring. MONET sampling sites are coloured blue.

\section{Conclusions}

The paper summarizes results of the ambient air monitoring activities in the Central and Eastern European region (CEEC), Central Asia, Africa and Pacific Islands driven by RECETOX under the common name of the MONET networks. For many of the participating countries these activities generated first data on the atmospheric levels of POPs. This was a reason why the background monitoring was accompanied with the screening of the extent of contamination in the individual countries. To carry these activities beyond the point of the first screening, best candidates for the background monitoring have to be selected in every region, and resources have to be sought to make the program sustainable.

Now, the harmonization of the monitoring activities in both parts of Europe to gain systematic information on the levels and trends of the atmospheric pollution over this continent has been started in 2009.

The EMEP stations in whole Europe participate in this now MONET phase which is focused on the improvement of the understanding to the sources, fate and transport of POPs in Europe and the providing rich information for the modeling databases.

\section{Acknowledgements}

This paper was/is supported by the CETOCOEN project (CZ.1.05/2.1.00/01.0001) of the European Structural Funds, the INCHEMBIOL project (MSM 0021622412) of the Ministry of Education of the Czech Republic and the Ministry of Environment of the Czech Republic (SP/1b1/30/07).

\section{References}

[1] UNEP Stockholm Convention on Persistent Organic Pollutants. Stockholm Convention on Persistent Organic Pollutants 2001, decisions, information documents, http://www.pops.int 
[2] Draft revised Guidance on the Global monitoring plan for persistent organic pollutants, UNEP, May 2011, UNEP/POPS/COP.5/INF/27

[3] Harner, T., Bartkow, M., Holoubek, I., Klanova, J., Wania, F., Gioia, R., Moeckel, C., Sweetman, A. J. \& Jones, K. C., Passive air sampling for persistent organic pollutants: Introductory remarks to the special issue. Environ. Pollut. 144, pp. 361-364, 2006.

[4] Peters, A. J., Lane, D. A., Gundel, L. A., Northcott, G. L. \& Jones, K. C., A comparison of high volume and diffusion denuder samplers for measuring semivolatile organic compounds in the atmosphere. Environ. Sci. \& Technol. 34, pp. 5001-5006, 2000.

[5] Harner, T., Farrar, N. J., Shoeib, M., Jones, K. C. \& Gobas, F., Characterization of polymer-coated glass as a passive air sampler for persistent organic pollutants. Environ. Sci. \& Technol. 37, pp. 2486-2493, 2003.

[6] Shahir, U. M., Li, Y. H. \& Holsen, T. M., Dry deposition of gas-phase polycyclic aromatic hydrocarbons to greased surrogate surfaces. Aerosol Sci. Technol. 31, pp. 446-455, 1999.

[7] Jaward, F. M., Farrar, N. J., Harner, T., Sweetman, A. J. \& Jones, K. C., Passive air sampling of polycyclic aromatic hydrocarbons and polychlorinated naphthalenes across Europe. Environ. Toxicol. Chem. 23, pp. 1355-1364, 2004.

[8] Harner, T., Shoeib, M., Diamond, M., Stern, G. \& Rosenberg, B., Using passive air samplers to assess urban - Rural trends for persistent organic pollutants. 1. Polychlorinated biphenyls and organochlorine pesticides. Environ. Sci. \& Technol. 38, pp. 4474-4483, 2004.

[9] Klanova, J., Kohoutek, J., Hamplova, L., Urbanova, P. \& Holoubek, I., Passive air sampler as a tool for long-term air pollution monitoring: Part 1. Performance assessment for seasonal and spatial variations. Environ. Pollut. 144, pp. 393-405, 2006.

[10] Cupr, P., Klanova, J., Bartos, T., Flegrova, Z., Kohoutek, J. \& Holoubek, I., Passive air sampler as a tool for long-term air pollution monitoring: Part 2. Air genotoxic potency screening assessment. Environ. Pollut. 144, pp. 406-413, 2006.

[11] Klánová, J., Čupr P., Holoubek, I., Borůvková, J., Přibylová, P., Kareš, R., Kohoutek, J., Dvorská, A. \& Komprda, J., Towards the Global Monitoring of POPs. Contribution of the MONET Networks. RECETOX MU Brno. RECETOX_TOCOEN REPORTS No. 357. 2009; ISBN 97880-210-4853-9; MASARYK UNIVERSITY 2009.

[12] Jaward, F. M., Farrar, N. J., Harner, T., Sweetman, A. J. \& Jones, K. C., Passive air sampling of PCBs, PBDEs, and organochlorine pesticides across Europe. Environ. Sci. \& Technol.38, pp. 34-41, 2004.

[13] Klánová, J., Čupr, P., Kohoutek, J. \& Harner, T., Assessing meteorological parameters on the performance of PUF disks passive air samplers for POPs. Environ. Sci. Technol. 42 (2), pp. 550-555, 2008.

[14] Klánová, J., Čupr P., Kohoutek, J., Holoubek, I.: Application of Passive Sampler for Monitoring of POPs in Ambient Air. Part I: Model 
monitoring network in the Czech Republic (MONET-CZ), 2006. RECETOX MU Brno. RECETOX-TOCOEN REPORTS No. 318. August 2007.

[15] Klanova, J., Cupr, P., Borůvková, J., Kohoutek, J., Kareš, R., Přibylová, P., Prokeš, R., Holoubek, I.: Application of passive sampler for monitoring of POPs in ambient air. IV. Model monitoring network in the Czech Republic (MONET-CZ 2007), 2008. Masaryk Univerzity, Brno, Czech Republic. ISBN 978-80-210-4696-2

[16] Klánová, J., Kohoutek, J., Kostrhounová, R. \& Holoubek, I., Are the residents of former Yugoslavia still exposed to elevated PCB levels due to the Balkan wars? Part 1: Air sampling in Croatia, Serbia, Bosnia \& Hercegovina. Environ. Int. 33 (6), pp. 719-726, 2007.

[17] Klánová, J., Kohoutek, J., Čupr, P. \& Holoubek, I. Are the residents of former Yugoslavia still exposed to elevated PCB levels due to the Balkan wars? Part 2: Passive air sampling network. Environ. Int. 33 (6), pp. 727 735, 2007.

[18] Klánová, J., Čupr P., Holoubek, I.: Application of Passive Sampler for Monitoring of POPs in Ambient Air. Part II: Pilot study for development of the monitoring network in the Central and Eastern Europe (MONET_CEEC), 2006. RECETOX MU Brno. RECETOX-TOCOEN REPORTS No. 319. August 2007.

[19] Klanova, J., Cupr, P., Holoubek, I., Borůvková, J., Přibylová, P., Kareš, R., Kohoutek, J.: Application of passive sampler for monitoring of POPs in ambient air. V. Pilot study for development of the monitoring network in the Central and Eastern Europe (MONET-CEEC 2007), 2008. Masarykova Univerzita, Brno, Czech Republic. ISBN 978-80-210-4697-9

[20] Klanova, J., Cupr, P., Holoubek, I., Borůvková, J., Přibylová, P., Kareš, R., Kohoutek, J., Dvorská, A., Tomšej, T., Ocelka, T.: Application of passive sampler for monitoring of POPs in ambient air. VI. Pilot study for development of the monitoring network in the African continent (MONET-AFRICA 2008), 2008. Masarykova Univerzita, Brno, Czech Republic, ISBN 978-80-210-4739-6

[21] Klánová J., Čupr, P., Holoubek, I., Borůvková, J., Kareš, R., Tomšej, T. \& Ocelka, T., Monitoring of persistent organic pollutants in Africa. Part 1: Passive air sampling across the continent in 2008. J. Environ. Monit., 11, pp. 1952-1963, 2009.

[22] Lammel, G., Dobrovolný, P., Dvorská, A., Chromá, K., Brázdil, R., Holoubek, I. \& Hošek, J., Monitoring of persistent organic pollutants in Africa. Part 2: Design of a network to monitor the continental and intercontinental background. J. Environ. Monit., 11, pp. 1964-1972, 2009.

[23] Klanova, J., Čupr P., Holoubek, I.: Application of passive sampler for determination of the POPs concentrations in ambient air. Part III: Pilot study in the Southern Pacific, Fiji, 2006. RECETOX MU Brno, RECETOX-TOCOEN REPORTS No. 320. August 2007. 